\title{
Magical manoeuvre: a 5-s instructor's intervention helps lightweight female rescuers achieve the required chest compression depth
}

\author{
Asta Krikscionaitiene ${ }^{a}$, Andrius Pranskunas ${ }^{b}$, Kestutis Stasaitis ${ }^{a}$, \\ Milda Dambrauskiene ${ }^{d}$, Nedas Jasinskas ${ }^{a}$, Zilvinas Dambrauskas ${ }^{c}$, \\ Egle Vaitkaitiene $^{\mathrm{a}}$, Jone Vencloviene ${ }^{\mathrm{e}}$ and Dinas Vaitkaitis ${ }^{\mathrm{a}}$
}

\begin{abstract}
Background Adequate chest compression (CC) depth is crucial for resuscitation outcomes. Lightweight rescuers, particularly women, are often unable to achieve the required $5-6 \mathrm{~cm} C C$ depth. This nonrandomized cohort study investigated new strategies to improve CC performance.
\end{abstract}

Objective To evaluate the effects of a 5-s instructor's intervention on the depth of CCs performed by female rescuers during standard video self-instruction basic life support training.

Methods Data were prospectively collected from January 2011 to January 2012 from 336 female medical and pharmacy students undergoing cardiopulmonary resuscitation (CPR) training at the Lithuanian University of Health Sciences. During the training process, the instructors performed a simple 5-s intervention (Andrew's manoeuvre) with all of the rescuers in the study group. The instructor pushed 10 times on the shoulders of each trainee while she performed CCs to achieve the maximal required compression depth. Immediately after training, the participants were asked to perform a 6-min basic life support test on a manikin that was connected to a PC with Skill Reporter System software; the quality of the participants' CPR skills was then evaluated.

\section{Introduction}

Chest compressions (CC) quality is a key determinant of good resuscitation outcomes for cardiac arrest patients [1]. Since the 2010 guidelines were released, the aim of CCs has been to push the chest to a depth of 5-6 cm [2]. This task is more difficult than previous guideline requirements [3,4]. Even healthcare professionals perform CCs with shallower-than-recommended depths, as shown in previous clinical cardiopulmonary resuscitation (CPR) studies in both in-hospital and out-of-hospital settings [5,6]. Potentially serious consequences can result from administering CCs of insufficient depth: low CC

This is an open-access article distributed under the terms of the Creative Commons Attribution-NonCommercial-NoDerivatives 3.0 License, where it is permissible to download and share the work provided it is properly cited. The work cannot be changed in any way or used commercially.
Results The CC depth in the study group increased by $6.4 \mathrm{~mm}(P<0.001)$ compared with the control group (52.9 vs. $46.6 \mathrm{~mm}$ ). A regression analysis showed that Andrew's manoeuvre increased the depth of the CCs among women by $14.87 \times(1-0.01 \times$ weight $) \mathrm{mm}$.

Conclusion A simple 5-s instructor's intervention during the CPR training significantly improved the performance of the female rescuers and helped them achieve the CC depth required by 2010 resuscitation guidelines. Andrew's manoeuvre is most effective among the women with the lowest body weight. European Journal of Emergency Medicine 21:424-428 @ 2014 Wolters Kluwer Health | Lippincott Williams \& Wilkins.

European Journal of Emergency Medicine 2014, 21:424-428

Keywords: basic life support, chest compressions, CPR quality, education, manikin

Departments of a Disaster Medicine, ${ }^{\mathrm{b}}$ Intensive Care, Crises Research Centre, ${ }^{c}$ Department of Surgery, Lithuanian University of Health Sciences, ${ }^{d}$ Hospital of Lithuanian University of Health Sciences Kaunas Clinics and ${ }^{\mathrm{e}}$ Department of Environmental Sciences, Faculty of Natural Sciences, Vytautas Magnus University, Kaunas, Lithuania

Correspondence to Asta Krikscionaitiene, MD, Department of Emergency and Disaster Medicine, Crises Research Centre, Lithuanian University of Health Sciences, Eiveniu 4-413, LT-50161 Kaunas, Lithuania

Tel: +370 616 33451; fax: + 370374 06559; e-mail: asta@smp.lt

Received 20 April 2013 Accepted 2 December 2013

depth is associated with suboptimal haemodynamics and poor outcomes after cardiac arrest [7-9].

While teaching CPR to adults, we noticed that individuals with lower weights, particularly women, had difficulty achieving adequate $\mathrm{CC}$ depths and they tired more quickly. Using standard video self-instruction training, the lightweight women in our previous study were unable to achieve CCs of adequate depth in accordance with the 2010 resuscitation guidelines [4]. Therefore, we investigated new strategies that could help improve their performances and achieve required CC depths of 5-6 cm.

We hypothesized that during standard video self-instruction, a short and simple instructor's intervention that emphasized the use of body weight during CCs could be effective in achieving the recommended depth of compressions in lightweight women.

DOI: 10.1097/MEJ.0000000000000107 


\section{Methods}

The Regional Ethics Committee approved the study (Protocol No. BC-MF-188/2011) and all participants provided written informed consent.

\section{Study participants \\ Inclusion and exclusion criteria}

The study was a nonrandomized cohort trial conducted in the Department of Disaster Medicine of the Lithuanian University of Health Sciences (LUHS) between January 2011 and January 2012. The participants included in this study were sixth-year female medical students and fourthyear female pharmacy students who underwent basic life support (BLS) training according to the LUHS curriculum.

The control group included the female students who underwent BLS training between January and June 2011. The study group included the female students who underwent BLS training from September 2011 to January 2012. A half of all the registered sixth-year medical students and all of the fourth-year pharmacy students were enrolled in each group.

We excluded the students who had already received practical training in BLS, advanced life support or the paramedic program. We also excluded from the study pregnant women and those students who refused to perform CCs because of previous trauma.

\section{Training process}

Groups of 20-24 students came to the Department of Disaster Medicine according to the schedule of LUHS. The students knew that they would be taught BLS skills and perform a BLS test, but they were blinded to the study's specific goals. Each participant was assigned an identification number and received an individual Resusci Anne manikin.

The 22 min video-based lecture titled AHA Family and Friends, CPR Anytime in Lithuanian was used to teach practical CPR skills. The instructors did not teach the students in our study. They were responsible for familiarizing the participants with the study process, monitoring protocol compliance and performing practical tests after training. The instructors refrained from giving comments about the participants' actions, correcting mistakes and answering questions during the training session. There were different instructors for training and testing sessions. The instructors who supervised training sessions were not aware of the goals of the study.

During training of the study group, we performed a simple 5-s intervention with all of the female participants. To achieve a maximal required compression depth, the instructor pushed on the shoulders of the trainees 10 times with gloved hands while the students performed CCs. The intervention was named Andrew's manoeuvre after the instructor who suggested this idea. Before the training, the students were warned that instructors would touch them with gloved hands and would perform this manoeuvre as a part of their training process. During the intervention, the instructors did not speak with the students and did not comment on their actions.

\section{Testing and data collection}

Every participant's BLS skills were individually tested immediately after the training session. The participants' resuscitation skills were evaluated using the same casebased scenario. We evaluated the students' CPR skills, including their initial assessment, calling emergency responders, CCs, ventilations and using the automated external defibrillator (AED). The evaluation lasted $6 \mathrm{~min}$. CCs were performed on a resuscitation manikin placed on the floor. Data were collected automatically using the Laerdal Resusci Anne Manikin PC Skill Reporter System (Laerdal Medical, Stavanger, Norway). After 2 min of CPR, the student was given an AED trainer. After the first defibrillation, the participant was expected to continue CPR for another 2 min following the AED's prompts. The test was stopped when the AED prompted the student to stand clear for a rhythm analysis 2 min after defibrillation began. Each participant had to complete two cycles (4 min) of CPR 30:2 (2 min before and 2 min after receiving the AED).

The criteria for inadequate depth were defined as $49 \mathrm{~mm}$ or less. The participants' demographic and anthropometric data, such as weight, height and BMI, were registered on data collection forms that were completed immediately after the test.

\section{Statistical analysis}

The statistical analyses were carried out using SPSS 13.0 software (SPSS Inc., Chicago, Illinois, USA). Continuous variables were compared using the MannWhitney $U$-test; the mean value and SE are presented. The relationship between the continuous variables was evaluated by Spearman's correlation coefficient. A multivariate linear regression was used to adjust for potential confounding factors; the interaction value between the factors in the model was included. A forward stepwise multivariate regression model was created using the $P$-value of 0.1 .

\section{Results}

According to the LUHS curriculum schedule, 471 students arrived and received training (Fig. 1). Overall, 36 students were excluded from the study. The participants included 336 female and 99 male students. The data from 336 female students who fulfilled the inclusion criteria were used for further analysis. We did not use data from the male students for further analysis in this study. There were 146 female students in the control group and 190 female students in the study group. A description of both the groups is presented in Table 1. 
Fig. 1

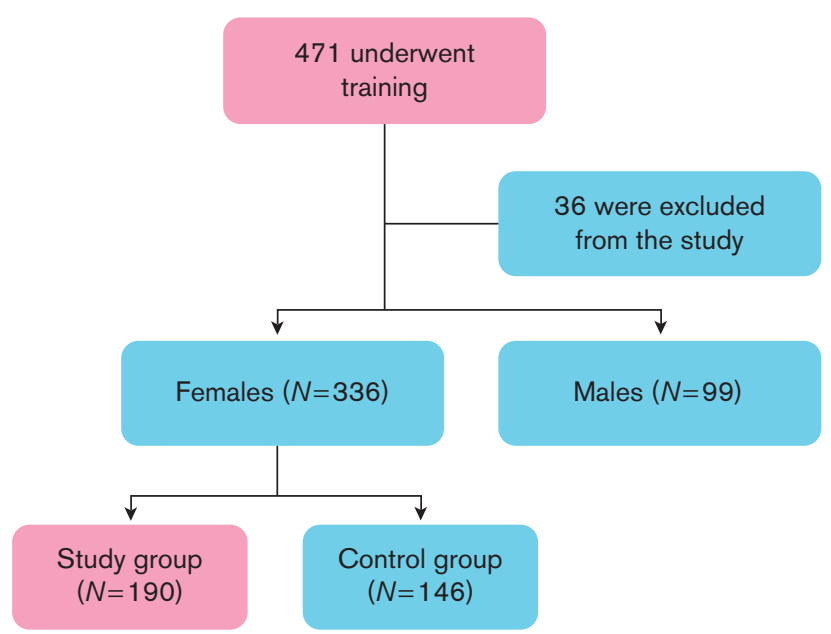

Inclusion of students in the control and study groups.

Overall, the CCs of the study group were significantly deeper compared with the control group. The female rescuers in the study group in which Andrew's manoeuvre was used achieved the CG depth required by the 2010 resuscitation guidelines (52.9 vs. $46.6 \mathrm{~mm}$ ).

In an evaluation of the association between compression depth and anthropometric data, the highest correlation was found between compression depth and body weight $(r=0.449)$. The correlation coefficient was 0.403 between the CG depth and body height and 0.316 between the CC depth and BMI. The association between compression depth and weight is presented as a scatter plot in Fig. 2 .

Weight, height and BMI were interdependent. The correlation coefficient was 0.706 between weight and height, 0.843 between weight and BMI, 0.254 between height and BMI. Therefore, initially, we included age, weight, height and Andrew's manoeuvre in the regression models evaluating the association of these factors with CC depth. However, during the statistical analysis, height was excluded from the multivariate linear regression model because it had a strong correlation with body weight $(r=0.706)$, and the collinearity statistic analysis showed a high variance inflation factor $(\mathrm{VIF}=2.01)$ when both factors were included in the model. Thus, only body weight was used for further statistical analysis because it had a better correlation with CC depth, and age was insignificant in the multivariate linear regression model (Table 2).

Using a regression model, we described the association between body weight, the use of Andrew's manoeuvre and compression depth in the regression equation:

$$
\text { DfCCs }=27.19+0.33 \times W+14.87 \times \mathrm{AM} \times(1-0.01 \mathrm{~W}) \text {, }
$$

where DfCCs is the depth of female CCs; W, weight of study participant; AM, Andrew's manoeuvre. AM applied: $\mathrm{AM}=1, \mathrm{AM}$ not applied: $\mathrm{AM}=0$.
Table 1 Comparison of the control and study groups

\begin{tabular}{|c|c|c|c|}
\hline$\underline{\text { Variables }}$ & Control group & Study group & $P$ \\
\hline Age (years) & $23.7(0.1)$ & $23.2(0.2)$ & 0.040 \\
\hline Weight (kg) & $59.9(0.7)$ & $61.5(0.8)$ & 0.117 \\
\hline Height $^{\mathrm{a}}(\mathrm{m})$ & $168(0.5)$ & $170(0.4)$ & 0.011 \\
\hline BMI & $21.1(0.2)$ & $21.3(0.2)$ & $>0.5$ \\
\hline Compression depth $(\mathrm{mm})$ & $46.6(0.7)$ & $52.9(0.5)$ & $<0.001$ \\
\hline Compression rate/min & $111.1(1.2)$ & $116.2(0.9)$ & $<0.001$ \\
\hline Leaning (\%) & $1.1(0.3)$ & $2.3(0.9)$ & 0.25 \\
\hline Average CC duty cycle (\%) & $42.6(0.4)$ & $41.7(0.4)$ & 0.13 \\
\hline
\end{tabular}

Data are presented as the mean (SE).

$\mathrm{CC}$, chest compression.

${ }^{\text {aT }}$ There was a statistically significant difference in height between the groups (median value 168.8 vs. $170 \mathrm{~cm}$ ) because of the four extra tall participants $(>184 \mathrm{~cm})$ in the study group. The regression model was tested after excluding these marginal cases; however, no significant changes were observed, and thus the original dataset is presented throughout the manuscript.

Fig. 2

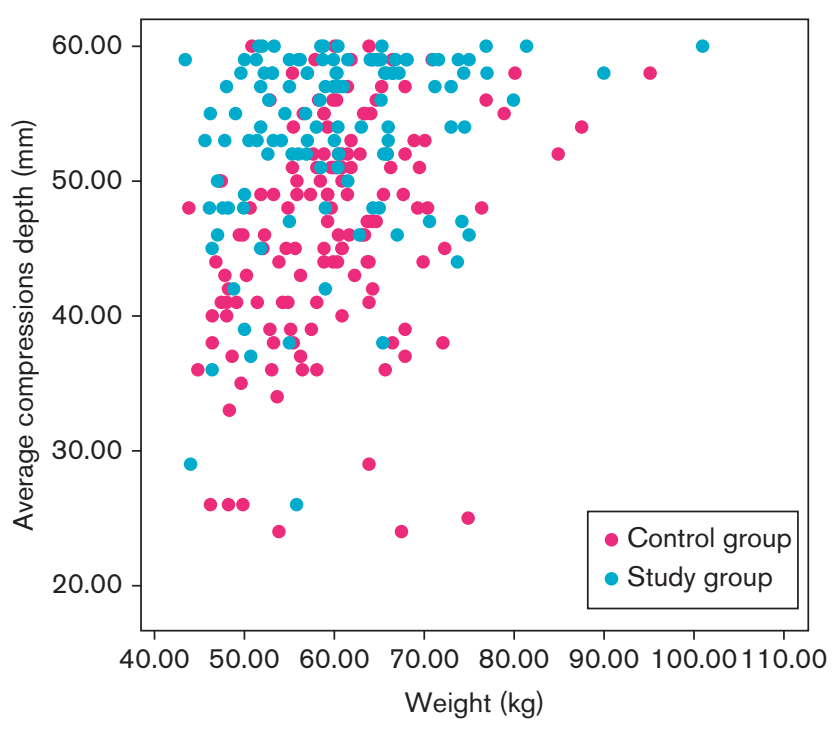

Scatter plot showing the distribution of chest compression depth of the female participants in the study and control groups.

The regression equation shows that in female rescuers, a $1 \mathrm{~kg}$ increase in body weight results in a $0.33 \mathrm{~mm}$ increase in $\mathrm{CG}$ depth. Andrew's manoeuvre adds an additional $14.87 \times(1-0.01 \times$ weight $) \mathrm{mm}$ to the depth of CCs for all of the female rescuers. Andrew's manoeuvre was most effective among the women with the lowest body masses. Multivariate linear regression model for CC depth should be used if body weight is less than $100 \mathrm{~kg}$.

\section{Discussion}

The aim of the study was to evaluate the effects of a 5-s instructor's intervention on the depth of CCs performed by female rescuers.

The data from the study suggest that Andrew's manoeuvre is effective. In the study group, the CC depths of the female rescuers were on average $6.4 \mathrm{~mm}$ 
Table 2 Multivariate linear regression model for chest compression depth

\begin{tabular}{|c|c|c|c|c|}
\hline & \multicolumn{2}{|c|}{ Unstandardized coefficients } & \multicolumn{2}{|c|}{ Standardized coefficients } \\
\hline & B & SE & $\beta$ & Significance \\
\hline Intercept & 27.188 & 4.151 & - & 0.000 \\
\hline Weight & 0.325 & 0.069 & 0.390 & 0.000 \\
\hline Andrew's manoeuvre & 14.872 & 5.172 & 0.921 & 0.004 \\
\hline Weight $\times$ Andrew's manoeuvre & -0.148 & 0.085 & -0.582 & 0.081 \\
\hline \multicolumn{5}{|c|}{$R^{2} 0.23323 ; \mathrm{SE}=7.0$} \\
\hline
\end{tabular}

deeper compared with the control group, and the CCs achieved the required depth of 5-6 cm. The results were statistically significant and clinically relevant not only because the female rescuers were able to achieve CCs of adequate depth in accordance with the 2010 resuscitation guidelines but also because Edelson et al. [10] have shown that every $5 \mathrm{~mm}$ increase in compression depth doubled the odds of successful defibrillation.

Andrew's manoeuvre appears to be an effective solution that could be used during the training of female rescuers, who are frequently unable to achieve sufficient CC depth compared with male rescuers [1,3,4,11-15]. Interestingly, it has been proven that the average rescuer is female $[16,17]$ and the average arrest victim is male $[11,18-20]$. Furthermore, some authors have suggested that the average rescuer can achieve adequate compression depth in a significant majority of women, but in only a relatively small percentage of men [11]; however, men represent the majority of all out-of-hospital arrest victims $[5,11,21]$.

Often, women experience difficulties in performing CCs with adequate depth because of their relatively low body mass. Our data also supported this notion as the regression analysis showed that among female rescuers, a $1 \mathrm{~kg}$ increase in body weight increased the CG depth by $0.33 \mathrm{~mm}$. Our previous research data and other authors confirmed that lightweight rescuers, who are often women or children, would most likely be unable to perform CCs according to the current guidelines [4,12,22,23].

Andrew's manoeuvre is most effective among women with the lowest body weight. The statistical analysis showed that women in the study group performed $6.4 \mathrm{~mm}$ deeper compressions compared with women in the control group $(52.9$ vs. $46.6 \mathrm{~mm})$. Furthermore, the regression analysis showed that with Andrew's manoeuvre, even the lightest study participant (with a body mass of $46 \mathrm{~kg}$ ) would be able to compress on average $8 \mathrm{~mm}$ deeper and meet the required standard; without this intervention, she performed shallower CCs of $42.37 \mathrm{~mm}$ depth.

Our data also showed the correlation between CG depth and both body height and BMI of the rescuer, as it is described by other authors [12,22,24]. However, the highest correlation was found between compression depth and body weight. Statistical analysis showed no differences between the control and the study groups for other CPR determinants such as leaning and average compression duty cycle, except for CG rate, which was affected by AED prompts.

Other studies documented a relationship between rate and depth [1,25-27], force and depth [28,29], and weight and force [28]. It is estimated that chest depression of $5 \mathrm{~cm}$ requires about $56.7 \mathrm{~kg}$ of body weight [28]. Geddes and colleagues found that only $9 \%$ of untrained laypersons and about $1 \%$ of trained rescuers performed CC with a force that exceeds their body weight. We also found that women with body weights less than $56 \mathrm{~kg}$ were 6.29 times more likely to produce insufficient CCs than women weighing $56-62.7 \mathrm{~kg}$ [4]. Obviously, one cannot influence the weight of a lightweight rescuer; therefore, new ways should be sought to help lighter rescuers achieve better results.

Further research is required to recommend the use of Andrew's manoeuvre during real-life resuscitation. Perhaps, in some instances, the adequate depth of the CCs could only be reached using four hands, with the second pair of hands placed on the shoulders of the rescuer performing CPR.

\section{Study limitations}

A major limitation of this study is the fact that the study groups were assessed at different time points and that this is a nonrandomized study. The participants' resuscitation skills were evaluated using a case-based scenario test, and their abilities during actual resuscitation are unknown. The maximum compression depth that can be measured on study manikins is $60 \mathrm{~mm}$. Consequently, when carrying out studies in accordance with the current 2010 resuscitation guidelines, we were unable to differentiate between a compression of adequate depth $(5-6 \mathrm{~cm})$ and an excessive compression $(>6 \mathrm{~cm})$. All of the study participants were young. In real-life settings, there is a particular need to train more individuals aged 55 or older as they are most likely to use CPR training [30]. In addition, the majority of study participants had normal body weights and BMIs; therefore, we could not evaluate the impact of excessive body weight on CCs. However, the effectiveness of Andrew's manoeuvre must be evaluated in the setting of prolonged resuscitation, and the long-term results should be assessed some months after the initial BLS training. The question remains whether Andrew's manoeuvre 
could be applied in real clinical situations or during outof-hospital CPR. A randomized study is needed for further evidence.

\section{Conclusion}

A simple 5-s instructor's intervention during CPR training significantly improved the performance of female rescuers and helped them achieve the CC depth required by the 2010 resuscitation guidelines. Andrew's manoeuvre is most effective among women with the lowest body masses.

\section{Acknowledgements}

The authors thank all of the study participants for their enthusiastic collaboration.

\section{Conflicts of interest}

There are no conflicts of interest.

\section{References}

1 Peberdy MA, Silver A, Ornato JP. Effect of caregiver gender, age, and feedback prompts on chest compression rate and depth. Resuscitation 2009; 80:1169-1174.

2 Koster RW, Sayre MR, Botha M, Cave DM, Cudnik MT, Handley AJ, et al. Part 5: adult basic life support: 2010 International consensus on cardiopulmonary resuscitation and emergency cardiovascular care science with treatment recommendations. Resuscitation 2010; 81 (Suppl 1):e48-e70.

3 Sayee N, McCluskey D. Factors influencing performance of cardiopulmonary resuscitation (CPR) by Foundation Year 1 hospital doctors. Ulster Med J 2012; 81:14-18.

4 Krikscionaitiene A, Stasaitis K, Dambrauskiene M, Dambrauskas Z, Vaitkaitiene $\mathrm{E}$, Dobozinskas $\mathrm{P}$, et al. Can lightweight rescuers adequately perform CPR according to 2010 resuscitation guideline requirements? Emerg Med J 2012; 30:159-160.

5 Wik L, Kramer-Johansen J, Myklebust H, Sorebo H, Svensson L, Fellows B, et al. Quality of cardiopulmonary resuscitation during out-of-hospital cardiac arrest. JAMA 2005; 293:299-304.

6 Abella BS, Alvarado JP, Myklebust H, Edelson DP, Barry A, O'Hearn N, et al. Quality of cardiopulmonary resuscitation during in-hospital cardiac arrest. JAMA 2005; 293:305-310.

7 Ornato JP, Levine RL, Young DS, Racht EM, Garnett AR, Gonzalez ER. The effect of applied chest compression force on systemic arterial pressure and end-tidal carbon dioxide concentration during CPR in human beings. Ann Emerg Med 1989; 18:732-737.

8 Bellamy RF, DeGuzman LR, Pedersen DC. Coronary blood flow during cardiopulmonary resuscitation in swine. Circulation 1984; 69:174-180.

9 Ristagno G, Tang W, Chang YT, Jorgenson DB, Russell JK, Huang L, et al. The quality of chest compressions during cardiopulmonary resuscitation overrides importance of timing of defibrillation. Chest 2007; 132:70-75.

10 Edelson DP, Abella BS, Kramer-Johansen J, Wik L, Myklebust H, Barry AM, et al. Effects of compression depth and pre-shock pauses predict defibrillation failure during cardiac arrest. Resuscitation 2006; 71:137-145.

11 Rottenberg EM. The need for a leftward shift in the flow-depth relationship during cardiopulmonary resuscitation. Resuscitation 2007; 72:350-352.
12 Ashton A, McCluskey A, Gwinnutt CL, Keenan AM. Effect of rescuer fatigue on performance of continuous external chest compressions over $3 \mathrm{~min}$. Resuscitation 2002; 55:151-155.

13 Verplancke T, De Paepe P, Calle PA, De Regge M, Van Maele G, Monsieurs KG. Determinants of the quality of basic life support by hospital nurses. Resuscitation 2008; 77:75-80.

14 Riegel B, Birnbaum A, Aufderheide TP, Thode HC Jr, Henry MC, Van Ottingham $\mathrm{L}$, et al. Predictors of cardiopulmonary resuscitation and automated external defibrillator skill retention. Am Heart J 2005; 150:927-932.

15 Christenson J, Nafziger S, Compton S, Vijayaraghavan K, Slater B, Ledingham R, et al. The effect of time on CPR and automated external defibrillator skills in the Public Access Defibrillation Trial. Resuscitation 2007; 74:52-62

16 Herlitz J, Svensson L, Holmberg S, Angquist KA, Young M. Efficacy of bystander CPR: intervention by lay people and by health care professionals. Resuscitation 2005; 66:291-295.

17 Swor R, Khan I, Domeier R, Honeycutt L, Chu K, Compton S. CPR training and CPR performance: do CPR-trained bystanders perform CPR? Acad Emerg Med 2006; 13:596-601.

18 Axelsson C, Claesson A, Engdahl J, Herlitz J, Hollenberg J, Lindqvist J, et al. Outcome after out-of-hospital cardiac arrest witnessed by EMS: changes over time and factors of importance for outcome in Sweden. Resuscitation 2012; 83:1253-1258.

19 Iwami T, Hiraide A, Nakanishi N, Hayashi Y, Nishiuchi T, Yukioka H, et al. Age and sex analyses of out-of-hospital cardiac arrest in Osaka, Japan. Resuscitation 2003; 57:145-152.

20 Chu KH, May CR, Clark MJ, Breeze KM. CPR training in households of patients with chest pain. Resuscitation 2003; 57:257-268.

21 McNally B, Robb R, Mehta M, Vellano K, Valderrama AL, Yoon PW, et al. Out-of-hospital cardiac arrest surveillance - Cardiac Arrest Registry to Enhance Survival (CARES), United States, October 1, 2005-December 31, 2010. MMWR Surveill Summ 2011; 60:1-19.

22 Jones I, Whitfield R, Colquhoun M, Chamberlain D, Vetter N, Newcombe R. At what age can schoolchildren provide effective chest compressions? An observational study from the Heartstart UK schools training programme. BMJ 2007; 334:1201.

23 Fleischhackl R, Nuernberger A, Sterz F, Schoenberg C, Urso T, Habart T, et al. School children sufficiently apply life supporting first aid: a prospective investigation. Crit Care 2009; 13:R127.

24 Larsen PD, Perrin K, Galletly DC. Patterns of external chest compression. Resuscitation 2002; 53:281-287.

25 Field RA, Soar J, Davies RP, Akhtar N, Perkins GD. The impact of chest compression rates on quality of chest compressions - a manikin study. Resuscitation 2012; 83:360-364.

26 Rawlins L, Woollard M, Williams J, Hallam P. Effect of listening to Nellie the Elephant during CPR training on performance of chest compressions by lay people: randomised crossover trial. BMJ 2009; 339:b4707.

27 Monsieurs KG, De Regge M, Vansteelandt K, De Smet J, Annaert E, Lemoyne $\mathrm{S}$, et al. Excessive chest compression rate is associated with insufficient compression depth in prehospital cardiac arrest. Resuscitation 2012; 83:1319-1323.

28 Geddes LA, Boland MK, Taleyarkhan PR, Vitter J. Chest compression force of trained and untrained CPR rescuers. Cardiovasc Eng 2007; 7: 47-50.

29 Tomlinson AE, Nysaether J, Kramer-Johansen J, Steen PA, Dorph E. Compression force-depth relationship during out-of-hospital cardiopulmonary resuscitation. Resuscitation 2007; 72:364-370.

30 Brennan RT, Braslow A. Are we training the right people yet? A survey of participants in public cardiopulmonary resuscitation classes. Resuscitation 1998; 37:21-25. 